CLINICAL STUDY

\title{
Demonstration of reduced in vivo surface expression of activating mutant thyrotrophin receptors in thyroid sections
}

\author{
M Sequeira $^{1,2}$, B Jasani ${ }^{3}$, D Fuhrer ${ }^{1}, \mathrm{M}_{\text {Wheeler }}{ }^{2}$ and M Ludgate ${ }^{1}$ \\ ${ }^{1}$ Departments of Medicine, ${ }^{2}$ Surgery and ${ }^{3}$ Pathology, University of Wales College of Medicine, Heath Park, Cardiff CF14 $4 X N$, UK \\ (Correspondence should be addressed to Marian Ludgate; Email: ludgate@cf.ac.uk)
}

\begin{abstract}
Objective: Thyroid function and growth are controlled by TSH. Hyperthyroidism can be due to Graves' Disease (GD), in which thyroid-stimulating antibodies mimic TSH, or gain-of-function mutations in the TSH receptor (TSHR). These activating mutations have poor surface expression when assessed in non-thyroidal cells in vitro but nothing is known of their in vivo behaviour. Several TSHR antibodies have been produced but none has been applied to thyroid paraffin sections. This study aimed to develop a technique suitable for use on paraffin sections and apply it to investigate TSHR expression in thyroids harbouring activating TSHR germline mutations compared with normal and GD thyroids. Design and methods: Immunocytochemistry coupled with antigen retrieval, using a spectrum of antibodies to the TSHR, was applied to paraffin sections of GD thyroid tissue. Subsequently, TSHR immunoreactivity was examined in three normal thyroids, three patients with GD and three patients with familial hyperthyroidism, due to different gain-of-function TSHR germline mutations, using the optimised protocol.

Results: Two antibodies, A10 and T3-495, to the extracellular domain (ECD) and membrane spanning region (MSR) of the TSHR respectively, produced specific basolateral staining of thyroid follicular cells. In normal and GD thyroids, basolateral staining with T3-495 was generally more intense than with A10, suggesting a possible surfeit of MSR over ECD. Graves' Disease thyroids have more abundant TSHR than normal glands. In contrast, thyroids harbouring gain-of-function mutations have the lowest expression in vivo, mirroring in vitro findings.

Conclusions: The development of an immunocytochemical method applicable to paraffin sections has demonstrated that different molecular mechanisms causing hyperthyroidism result in the lowest (mutation) and highest (autoimmunity) levels of receptor at the thyrocyte surface.
\end{abstract}

European Journal of Endocrinology 146 163-171

\section{Introduction}

The growth and function of the thyroid gland are controlled by thyrotrophin (TSH), acting via its G protein coupled receptor (TSHR), to increase intracellular levels of cAMP (1). The TSHR shares homology with the receptors for the other glycoprotein hormones, luteinising hormone (LH) and follicle-stimulating hormone (FSH). All three are characterised by a large extracellular domain (ECD), responsible for high affinity ligand binding, and a seven membrane spanning region (MSR) which connects with the signal transduction machinery of the cell (2).

The low physiological levels of TSHR expression have hampered ex vivo examination of its structure. Several investigators have studied TSHR expression in various thyroid pathologies, mainly using RT-PCR and other transcript-based methods (3-7) but very little information is available evaluating receptor protein levels (8) due to the lack of suitable probes.
Since the cloning of the TSHR, several different approaches have been applied to the generation of polyclonal and monoclonal antibodies (mabs), including immunisation with synthetic peptides, receptor fragments or ECD (9-11) produced in bacteria or insect cells and genetic immunisation (12). A range of valuable reagents for use in Western blot, flow cytometry and immunoprecipitation has been produced. Some of the mabs have been used to visualise the receptor in intact thyroid glands by immunocytochemistry. The majority of reports have studied cryostat sections of snap-frozen thyroid tissue $(10,13)$ and not formalin fixed paraffin sections. As a consequence, the wealth of information in archival material has not been available.

There is some evidence that the TSHR may exist as two subunits at the cell surface. Analysis of thyroid membranes suggests that the MSR is more abundant than the ECD, particularly in the presence of TSH, leading to the proposal that shedding of the ECD may be a 
mechanism of receptor activation $(10,14)$. Whether this mechanism is in operation in pathological conditions, in which cAMP levels are elevated without the physiological interaction of TSH with the TSHR resulting in hyperthyroidism, has not been investigated.

Depending on the iodide intake of a given population, the most common cause of hyperthyroidism is Graves' Disease (GD), in which thyroid-stimulating antibodies (TSab) mimic the action of TSH (15). More recently, a second thyrotoxic mechanism has been defined at the molecular level. Point mutations in the TSHR, resulting in a single amino acid change, were shown to produce constitutive activity in the receptor, i.e. permanent activation of the adenylate cyclase (which produces cAMP) even in the absence of TSH. This was first described as somatic mutation occurring in single toxic adenomas (16) but has since also been found in some toxic multinodular goitre lesions (17). Germline mutations in the TSHR have also been identified in familial non-autoimmune hyperthyroidism, in which it displays autosomal dominant inheritance, and in cases of sporadic neonatal thyrotoxicosis, which may become familial in time $(18,19)$. The age of onset of symptoms can vary widely, even in the same family (20).

Currently, in excess of 25 different gain-of-function mutations, chiefly located in the MSR of the receptor implicated in signal transduction, have been described. Both the plethora of mutations (21) and the high prevalence of $\mathrm{GD}(0.2 \%$ in men, $2 \%$ in women) attests to the extreme lability of the TSHR, a feature which is not shared by the other glycoprotein hormone receptors (22).

A common feature of activating mutant forms of TSHR is their reduced surface expression compared with the wild type, when analysed by flow cytometry of transfected non-thyroidal cells $(23,24)$. Whether this reflects the situation in vivo has not been possible to test in the absence of relevant frozen thyroid tissue or an immunocytochemical method suitable for fixed tissue.

In this study we report the development of an immunocytochemical method for the TSHR suitable for use on archival paraffin-embedded sections, using a microwave heat antigen retrieval technique, and its application to the investigation of TSHR expression in hyperthyroidism, as a consequence of GD and activating TSHR mutations, compared with normal thyroid glands.

\section{Methods}

\section{Case and tissue material}

Tissue samples Formalin-fixed, paraffin-embedded pathological specimens, from nine patients comprising three with GD, three having a normal thyroid lobe and three with an activating TSHR germline mutation were retrieved from the pathology archives of the
University Hospital of Wales, Cardiff, the Universities of Leipzig and Freiburg in Germany. The three patients with a normal thyroid histopathology were operated for a completion total thyroidectomy having previously undergone a lobectomy for a follicular carcinoma. The initial histological sections stained with haematoxylin and eosin were reviewed to confirm normal morphology in these three patients and the relevant pathology in the others. Details of the histopathology are listed in Table 1.

Patient characteristics Details of the patient's age at surgery, sex, thyroid status at diagnosis, immediate pre-operative thyroid function tests, TSab assay, previous relevant anti-thyroid therapy, immediate preoperative preparation, diagnosis and histopathology are listed in Table 1. The characteristics of the TSHR germline mutant forms studied are summarised in Table 2.

\section{Antibodies used in the study}

A range of TSHR polyclonal and monoclonal antibodies were evaluated; their details are given in Table 3.

\section{Immunocytochemistry}

In pilot experiments, as a screening procedure the monoclonal antibodies were used at a 1:20 dilution and the polyclonal antibodies at a 1:500 dilution on archival formalin-fixed paraffin-embedded GD sections. A minor modification of an antigen retrieval method (25) developed and refined in the Department of Pathology was utilised as standard procedure for all the experiments. This consisted of heating the sections in a microwave at full power for $25 \mathrm{~min}$, in a $1 \mathrm{mmol} / \mathrm{l}$ EDTA solution at $\mathrm{pH}$ 8.0.

The antibodies selected for further study were then titrated in doubling dilutions. Optimal concentration of primary antibody was determined at a dilution where only specific staining of follicular cells was visible and the background stroma and connective tissue was negative.

Antibody specificity was also established, using the optimal concentrations of the two antibodies selected for further study, on a range of paraffin-embedded tissue controls after both antigen retrieval and endogenous biotin blockade (see below). These included sections from the testis, appendix, liver, fallopian tube, skin, prostate, gall bladder, uterus and lymph nodes.

Immunohistochemical analysis Utilising the optimised immunocytochemical protocol, TSHR expression in the three subsets of patients was studied by staining with the two monoclonal antibodies selected, i.e. A10 and T3-495. A10 was used at a 1:320 and T3-495 at a 1:400 dilution. Diluent without any antibody was utilised as negative control. The test was repeated 
Table 1 Clinical characteristics of the patients studied. Abbreviations used: T $_{4}$, serum free thyroxine; TSH, serum TSH; TSab, TSHR-stimulating antibody assay; Tg, thyroglobulin; TPO, thyroperoxidase; CTT, completion total thyroidectomy; STT, subtotal thyroidectomy; NTT, near-total thyroidectomy; NAH, non-autoimmune hyperthyroidism.

\begin{tabular}{|c|c|c|c|c|c|c|c|c|c|c|}
\hline No. & $\begin{array}{l}\text { Age } \\
\text { at surgery }\end{array}$ & Sex & $\begin{array}{l}\text { Thyroid status } \\
\text { at diagnosis }\end{array}$ & $\begin{array}{l}\text { Pre-op. } \mathbf{T}_{4} \\
\text { (normal: } \\
8-26 \mathrm{pmol} / \mathrm{l})\end{array}$ & $\begin{array}{l}\text { Pre-op. TSH } \\
\text { (normal: } \\
<5 \mathrm{mU} / \mathrm{l})\end{array}$ & $\begin{array}{l}\text { TSab assay } \\
\text { (normal: } \\
<10.0 \%)\end{array}$ & $\begin{array}{l}\text { Anti-Tg/ } \\
\text { TPO Abs }\end{array}$ & $\begin{array}{l}\text { Pre-op. } \\
\text { treatment }\end{array}$ & $\begin{array}{l}\text { Surgery/indication } \\
\text { for surgery }\end{array}$ & $\begin{array}{l}\text { Hemotoxylin } \\
\text { and eosin }\end{array}$ \\
\hline 1 & 20 & $\mathrm{~F}$ & Euthyroid & 16 & 1.7 & N/A & N/A & Nil & CTT/Follicular $\mathrm{Ca}$ & Normal thyroid tissue \\
\hline 2 & 70 & $\mathrm{~F}$ & Euthyroid & 19 & 1.4 & $\mathrm{~N} / \mathrm{A}$ & $\mathrm{N} / \mathrm{A}$ & Nil & CTT/Follicular Ca & Normal thyroid tissue \\
\hline 3 & 35 & M & Euthyroid & 14 & 1.8 & N/A & N/A & Nil & CTT/Follicular Ca & Normal thyroid tissue \\
\hline 4 & 69 & $\mathrm{~F}$ & Hyperthyroid & 59.2 & 0.02 & $82.6 \%$ & $\begin{array}{l}\text { Anti-TPO } \\
\text { positive }\end{array}$ & $\begin{array}{l}\text { Carbimazole } \\
\text { and thyroxine }\end{array}$ & STT/GD & $\begin{array}{l}\text { Combined thyroiditis and } \\
\text { Graves' (hashitoxicosis), } \\
\text { oncocytic change and } \\
\text { nodularity of thyroid. GD } \\
\text { and thyroiditis }\end{array}$ \\
\hline 5 & 44 & $F$ & Hyperthyroid & 10.2 & 0.10 & $88.3 \%$ & $\begin{array}{l}\text { Anti-TPO } \\
\text { positive }\end{array}$ & $\begin{array}{l}\text { Carbimazole } \\
\text { and thyroxine }\end{array}$ & STT/GD & $\begin{array}{l}\text { Consistent with Graves', } \\
\text { mild to moderate atypia, } \\
\text { chronic inflammatory cells. GD }\end{array}$ \\
\hline 6 & 28 & $\mathrm{~F}$ & Hyperthyroid & 14.9 & 0.34 & $66.6 \%$ & Both postive & $\begin{array}{l}\text { Carbimazole } \\
\text { and thyroxine }\end{array}$ & STT/GD & $\begin{array}{l}\text { Consistent with Graves', } \\
\text { prominent lymphoid aggregates. GD }\end{array}$ \\
\hline 7 & 11 & $\mathrm{M}$ & Hyperthyroid & 14.3 & 2.7 & Negative & Negative & $\begin{array}{l}\text { Methimazole } \\
\text { and thyroxine }\end{array}$ & $\begin{array}{l}\text { NTT/NAH } \\
\text { (mutation L629F) }\end{array}$ & $\begin{array}{l}\text { Mild to moderate degree of } \\
\text { nodular hyperplasia with } \\
\text { variable-sized colloid-filled } \\
\text { follicular profile }\end{array}$ \\
\hline 8 & 2 & $\mathrm{M}$ & Hyperthyroid & 76.8 & $<0.04$ & Negative & Negative & $\begin{array}{l}\text { PTU/Lugol's } \\
\text { iodine }\end{array}$ & $\begin{array}{l}\text { NTT/NAH } \\
\text { (mutation S505N) }\end{array}$ & $\begin{array}{l}\text { Mild to moderate degree of } \\
\text { nodular hyperplasia with } \\
\text { variable-sized colloid-filled } \\
\text { follicular profile }\end{array}$ \\
\hline 9 & 26 & $F$ & Hyperthyroid & 17.0 & 0.04 & $3.8 \%$ & Positive & Carbimazole & $\begin{array}{l}\text { STT/NAH } \\
\text { (mutation M463V) }\end{array}$ & $\begin{array}{l}\text { Mild atypia of follicular epithelium } \\
\text { consistent with carbimazole therapy }\end{array}$ \\
\hline
\end{tabular}


Table 2 Characterisation of mutants compared with the wild-type receptor. Thyroid glands harbouring three different activating germline mutations (leucine 629 replaced by phenylalanine; serine 505 replaced by asparagine; methionine 463 replaced by valine) have been investigated. All three mutants have been compared previously with the wild type (WT) receptor, for basal cAMP levels and cell surface expression, by transient transfection studies in non-thyroidal (mostly COS) cells. Flow cytometry (\% of WT) refers to the surface expression of the mutant receptor, taking the WT as 100\% and using either the BA8 or 2C11 TSHR monoclonal as defined. cAMP (\% of basal) increase refers to the basal cAMP produced by transient transfection with the mutant receptor compared with the WT, which is $100 \%$. The cAMP levels have either been measured directly in a RIA or indirectly using a cAMP-responsive luciferase reporter as described in the relevant references.

\begin{tabular}{|c|c|c|c|c|c|}
\hline \multirow[b]{2}{*}{ Mutant } & \multirow{2}{*}{$\begin{array}{c}\text { Flow Cytometry } \\
\text { (\% of WT) }\end{array}$} & \multirow{2}{*}{$\begin{array}{l}\text { Antibody used in } \\
\text { flow cytometry }\end{array}$} & \multicolumn{2}{|c|}{ cAMP (\% of basal) } & \multirow[b]{2}{*}{ Reference } \\
\hline & & & cAMP assay & Luminescent assay & \\
\hline L629F & 63 & $2 \mathrm{C} 11$ & $\sim 600$ & $\sim 170$ & 24 \\
\hline S505N & 79 & $2 \mathrm{C} 11$ & $\sim 600$ & & 30 \\
\hline M463V & 50 & BA8 & & $\sim 200$ & 29 \\
\hline
\end{tabular}

in duplicate and results reported are the mean of the two readings. Two of the authors (MS and BJ), who were blinded to the diagnosis, independently scored each section and results from both assessors were pooled to arrive at the final score. Any discrepancies between the two authors were resolved by a joint assessment of the sections

The streptavidin-biotin complex immunoperoxidase procedure was, in brief, as follows: the sections were de-paraffinised, then incubated in methanol $(98.4 \%)$ and hydrogen peroxide (1.6\%) to block endogenous peroxidase activity and then subjected to antigen retrieval. Antigen retrieval was performed by microwaving at full power for $25 \mathrm{~min}$ in $1 \mathrm{mmol} / \mathrm{l} \mathrm{EDTA}$ solution. Endogenous biotin activity was blocked using a commercially prepared avidin/biotin blocking kit (Vector Labs, Peterborough, UK) by incubating the slides for $15 \mathrm{~min}$ each in two or three drops per slide of Avidin followed by Biotin. The slides were thoroughly washed in PBS between each step and prior to application of the primary antibody. The sections were then incubated overnight at $4{ }^{\circ} \mathrm{C}$ with the primary antibody. Multi-Link biotinylated anti-IgG (BioGenex, San Ramon, CA, USA) and streptavidin peroxidase label (BioGenex) were utilised at a 1:40 dilution, each for $30 \mathrm{~min}$ at room temperature. PBS was utilised to wash sections between each step of the procedure. The chromogenic substrate utilised was diaminobenzidine tetrahydrochloride (DAB) made up in PBS with two drops of hydrogen peroxide. The sections were counterstained with Harris haematoxylin.

Sections were analysed as to the homogeneity and distribution of staining, pattern of cytoplasmic and cell membrane staining, intensity of staining and staining of plasma and blood elements. Intensity of staining was scored based on the power of the lens needed to clearly demarcate stained (brown) cells from unstained (blue) background as follows: $\times 4-$ strong staining $(+++), \times 10-$ moderate staining $(++), \times 25-$ weak staining $(+), \times 40-$ virtually absent $( \pm)$, and no staining whatsoever at any power - absent $(-)$.

\section{Results}

\section{Epitope retrieval permits immunostaining of the TSHR on thyroid paraffin sections}

Figure 1A shows the basolateral staining obtained in a normal thyroid gland following immunocytochemistry using A10 and T3-495 in the optimised protocol. Overall, the intensity of staining seen with A10 was stronger than that observed with T3-495, although the latter produced more abundant membrane-associated staining. This staining was specific to the thyroid and none of the other tissues studied, including testis, appendix, liver, fallopian tube, skin, prostate, gall bladder, uterus and lymph nodes, demonstrated any significant staining with either antibody (data not shown).

\section{TSHR expression levels vary in hyperthyroid glands having different pathogenesis}

The nine sections from normal thyroids and hyperthyroid glands from GD and activating germline TSHR mutations were analysed in parallel. Wide variations

Table 3 Antibodies used in this study and their characteristics.

\begin{tabular}{lllll}
\hline Antibody & \multicolumn{1}{c}{ How produced } & Subclass & Epitope & Reference \\
\hline BA8 & Genetic immunization & IgG2a & Conformational & 12 \\
3G4 & Genetic immunization & IgG2a & ECD 354-359 & 12 \\
A10 & ECD from insect cells & IgG2b & ECD 22-35 & 11 \\
T3-495 & MSR 604-764 in bacteria & IgG1 & MSR 604-764 & 10 \\
$59 N$ & Peptide antibody in rabbits & N/A & ECD 326-345 & 9 \\
60N & Peptide antibody in rabbits & N/A & & 9 \\
\hline
\end{tabular}


Table 4 Immunocytochemical staining of normal, Graves' and mutant receptor thyroids with monoclonal antibodies A10 and T3-495. Distribution: scored as a percentage of the entire section showing the staining. C - Cytoplasmic, M - membranous. Intensity of staining: the results were scored based on the power of the lens needed to clearly demarcate stained (brown) cells from unstained (blue) background as follows: $\times 4-$ strong staining $(+++), \times 10-$ moderate staining $(++), \times 25-$ weak staining $(+), \times 40-$ virtually absent $( \pm)$ and no staining whatsoever at any power - absent $(-)$. Pattern: D - diffuse, MF - multifocal, F - focal, VF - very focal, PZ - peripheral (subcapsular) zonation. PMN - peripheral white blood elements.

\begin{tabular}{|c|c|c|c|c|c|c|c|c|c|c|c|c|c|c|}
\hline \multirow[b]{3}{*}{ No. } & \multicolumn{7}{|c|}{ A10 } & \multicolumn{7}{|c|}{ T3-495 } \\
\hline & \multicolumn{2}{|c|}{ Distribution (\%) } & \multicolumn{2}{|c|}{ Intensity } & \multicolumn{2}{|c|}{ Pattern } & \multirow[b]{2}{*}{ Remarks } & \multicolumn{2}{|c|}{ Distribution } & \multicolumn{2}{|c|}{ Intensity } & \multicolumn{2}{|c|}{ Pattern } & \multirow[b]{2}{*}{ Remarks } \\
\hline & C & $M$ & C & $\mathrm{M}$ & C & $M$ & & C & $M$ & C & $M$ & C & M & \\
\hline
\end{tabular}

Normal

2

Graves'

Mutant receptor

7 Mutant receptor

$\begin{array}{llllll}80-90 & 10-25 & +/++ & + & \text { D } & \text { MF } \\ 90 & 50 & ++ & ++ & \text { D } & \text { MF } \\ 90 & 5-10 & \pm /+ & \pm /+ & \text { D } & \text { F }\end{array}$

Plasma +++.

Patchy membrane expression.

Plasma +++.

Patchy membrane expression.

Plasma + .

Patchy membrane expression.

$\begin{array}{llllll}0 & 30-40 & - & +/++ & - & \text { MF } \\ 10-20 & 80 & - & +/++ & - & \text { D } \\ 20-30 & 30-40 & \pm /+ & \pm /+ & \text { MF } & \text { MF }\end{array}$

Plasma-.

Entire basolateral.

Plasma-.

Entire basolateral.

Plasma-.

Patchy membrane expression.

\begin{tabular}{|c|c|c|c|c|c|}
\hline $5-10$ & +/++ & + & $\mathrm{D}$ & VF/PZ & $\begin{array}{l}\text { Plasma +++. } \\
\text { Speckled cytoplasm. }\end{array}$ \\
\hline 50 & ++ & $+/++$ & $D$ & MF & רa ++ . \\
\hline
\end{tabular}

Plasma ++.

Speckled cytoplasm.

PMN-.

Fine granular cytoplasm.

$>90 \quad 5-10 \quad+/ \pm \quad+/++\quad$ D VF/PZ Plasma and PMN-.

Speckled cytoplasm

Plasma and PMN-.

15-20 25-40 + to + + $1++\quad$ F/PZ Speckled cytoplasm.

Fine granular cytoplasm.

\begin{tabular}{|c|c|c|c|c|c|c|c|c|c|c|}
\hline 90 & $5-10$ & $\pm /+$ & D & VF & Plasma ++ & $80-90$ & $5-10$ & + & $\pm /+$ & $\mathrm{D}$ \\
\hline 90 & $<1$ & $\pm /+$ & D & VF/PZ & PMNs - & 0 & 0 & - & - & - \\
\hline $40-50$ & 0 & +/++ & MF & - & Plasma \pm & 0 & 0 & - & - & - \\
\hline
\end{tabular}



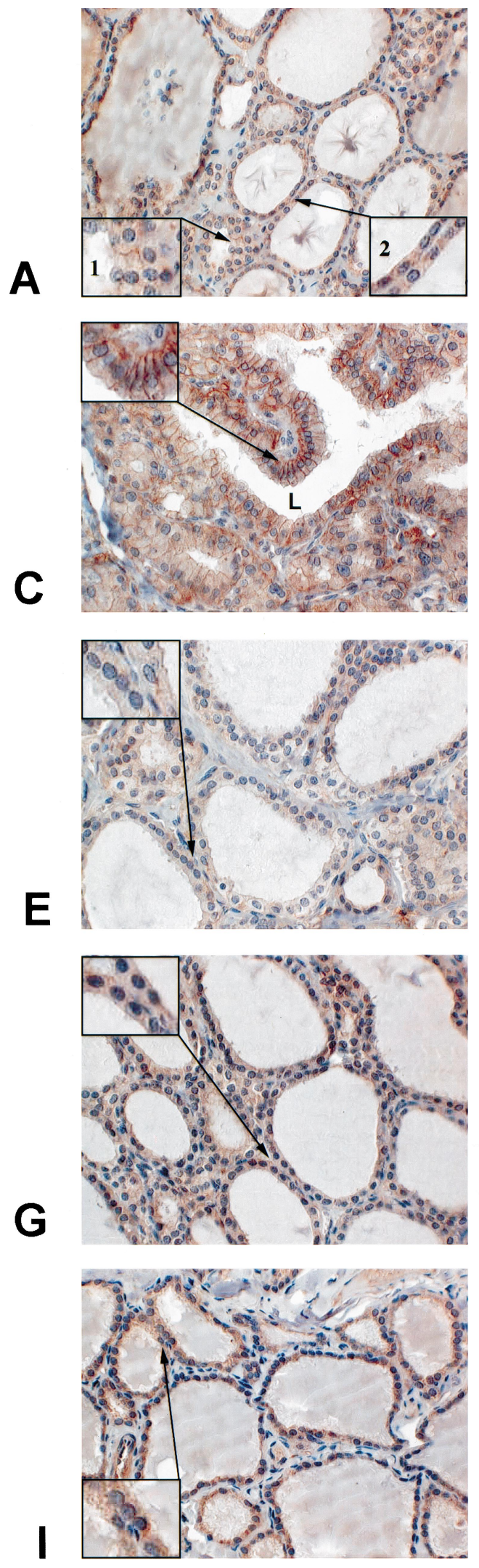
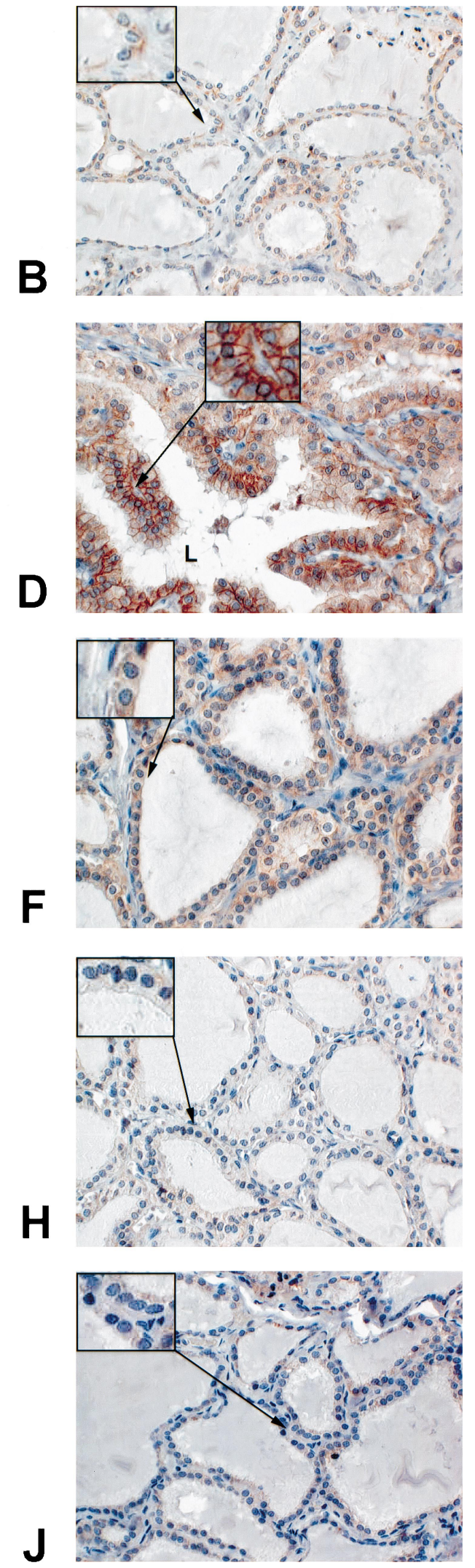
in the staining intensity and patterns of staining were observed. On the whole, the most intense staining was present in the GD thyroids (moderate to occasional strong staining) and least intense on the three thyroids harbouring germline TSHR mutations (very weak to weak staining) with normal thyroids weaker than patients with GD.

In normal thyroids, staining with A10 was more cytoplasmic than membranous which, if present, was patchy and discontinuous. The intensity of staining ranged from weak to moderate. Consistent, moderate to strong plasma and occasional colloid staining was noted in this and all other thyroid tissues studied with this antibody. Staining of peripheral white blood elements was difficult to comment on because of adherence of plasma to these cells and the absence of these elements in some of the other thyroid pathologies.

Staining of normal thyroids with T3-495 was predominantly associated with the membrane in two of the three patients and covered the entire basolateral surface. In contrast, in case 3, even though the membrane-associated staining was more abundant than the cytoplasmic, it was discontinuous and not over the entire basolateral surface as in cases 1 and 2 . No plasma or colloid-associated staining was observed in this or any other type of tissues studied when applying this antibody.

In the Graves' group as a whole, the intensity of membrane-associated staining noted was moderate to strong although case 4 , who displayed the weakest staining, was still hyperthyroid at the time of surgery. When compared with normal thyroid tissue, more cytoplasmic than membranous staining was evident with both A10 and T3-495, with over 90\% of the section displaying cytoplasmic staining with T3-495, in two of three cases. In common with normal thyroid tissue, membrane-associated staining was more intense with T3-495 than with A10.

In the thyroids harbouring mutant TSHR, the picture was dissimilar to the above two scenarios. Most staining, if present, was in the cytoplasmic compartment, where it could reach the intensity obtained in normal thyroids. In contrast, weak membranous staining was demonstrated only in the thyroid of patient 7 and was confined to the hyperplastic areas within the section. There was a complete absence of staining for T3-495 in patients 8 and 9, the former being hyperthyroid at the time of surgery and the only patient treated pre-operatively with Lugol's iodine. Overall, the intensity of staining ranged from absent to weak.

Representative sections stained for A10 and T3-495 of normal thyroid, Graves' thyroid and all three mutant thyroids are shown in Fig. 1A-J. The results are summarised in Table 4.

\section{Discussion}

Our results indicate that it is possible to assess TSHR protein expression in paraffin-embedded sections of formalin-fixed thyroid tissue, using an antigen retrieval protocol which has previously been successfully applied to study oestrogen and progesterone receptors and a wide variety of other antigens in archival tissue (26).

Not all antibodies evaluated were susceptible to the method but the two selected, A10 (11) and T3-495 (10) produced basolateral staining of most of the thyroid specimens examined, consistent with the known location of the TSHR. Of interest, one of the T3 family of antibodies was used in an earlier study of receptor expression in paraffin sections of thymus, adrenal and kidney, without recourse to an antigen retrieval method (27). Unfortunately, the staining obtained on paraffin sections of thyroid tissue was not shown or discussed so it is difficult to evaluate the work in the context of the present study in which specific receptor staining was restricted to the thyroid gland. Previously we have applied A10 to cryostat sections of Graves' thyroid (28), and found that the intensity of membrane staining in the present study is comparable to that obtained in the earlier work. In contrast, cytoplasmic staining with A10 is more abundant on paraffin than on cryostat tissue sections. We also examined frozen orbital fat tissues and demonstrated marked A10 immunoreactivity in samples from patients with thyroid eye disease but only faint staining in normal orbital fat samples (28). Parallel investigation of cryostat sections of abdominal fat showed even less staining (not

Figure 1 (Opposite) Representative sections of normal (patient 3), Graves' (patient 5) and all three mutant thyroids (patients 7-9) stained with A10 and T3-495 (magnification $\times 100$ ). (A) Normal thyroid stained with A10 showing membranous (see the magnified image in inset 1) and diffuse cytoplasmic (see the magnified image in inset 2) staining. (B) Normal thyroid stained with T3-495 showing patchy and almost exclusively membrane staining (see the magnified image in the inset). The intensity of staining is equal to that seen in $(A)$, in which the membrane staining is largely masked by the cytoplasmic staining. (C) Graves' thyroid stained with A10 showing more intense but discontinuous membrane and weaker cytoplasmic staining (see the magnified image in the inset) than in $(A)$ or (B). $L$ = lumen. (D) Graves' thyroid stained with T3-495 showing strong continuous membrane staining (see the magnified image in the inset) which is more complete and stronger than that seen in (C). L = lumen. (E) Mutant L629F showing weak diffuse cytoplasmic staining (see the magnified image in the inset) with A10. (F) Mutant L629F showing weak cytoplasmic staining (see the magnified image in the inset) and focal hyperplastic regions with minor amounts of membrane staining with T3-495. (G) Mutant S505N showing diffuse weak cytoplasmic staining (see the magnified image in the inset) with A10. (H) Mutant S505N showing apparent absence of any cytoplasmic or membranous staining (see the magnified image in the inset) with T3-495. (I) Mutant M463V showing moderate cytoplasmic staining (see the magnified image in the inset) with A10. (J) Mutant M463V showing apparent absence of any cytoplasmic or membranous staining (see the magnified image in the inset) with T3-495. 
reported) and in the current study, fat tissue present in the non-thyroidal specimens examined were negative. This suggests that the antigen retrieval protocol is less sensitive than immunostaining of cryostat sections but it provides a means of comparing TSHR expression in archive material from varying thyroid pathologies, including hyperthyroidism as the result of gain-of-function TSHR mutation.

It is possible that antibodies raised against the wildtype receptor will fail to recognise mutated TSHR. A number of studies have applied a variety of TSHR antibodies in flow cytometry analysis of surface expression of various mutant TSHR, including the mutants examined in the present work $(23,24,29,30)$. The antibodies used have been predominantly BA8 and $3 \mathrm{G} 4 / 2 \mathrm{C} 11$, the former recognises conformation and the latter two a linear epitope in the ECD of the TSHR. To our knowledge, to date only one mutant, Ile167Asn, resulting in loss of TSHR function (31), has failed to be detected in flow cytometry using BA8, whose conformational epitopes might be more susceptible to disruption by mutation than those recognising linear epitopes, such as the antibodies amenable to use on paraffin sections, A10 and T3-495. The obvious exception is T3-495 applied to sample 7, which harbours a L629F mutation falling within the epitope recognised by this antibody. As can be seen from the results, sample 7 was the only 'mutant thyroid' in which some staining, albeit weak, was obtained with this antibody. The staining was predominantly cytoplasmic, suggesting that the receptor is indeed detected by the antibody but fails to reach the cell surface.

In the normal and Graves' thyroids, membrane staining was more intense using the T3-495 antibody which detects the MSR, compared with A10 which binds the amino terminus of the ECD. In contrast, staining of the plasma was observed with A10 but not T3-495. Whether the apparent excess of MSR is further support for the shedding of the ECD from the thyrocyte surface, or merely reflects the relative affinities of the antibodies used, remains open to debate.

Immunoreactivity in the Graves' thyroids is modified both by the autoimmune process and treatment for hyperthyroidism, yet we found the highest receptor protein levels in these glands. This is in agreement with a previous study comparing TSHR expression in cryostat sections of different thyroid pathologies, in which GD demonstrated the most intensive staining (13) and is supported by ongoing quantitative real-time PCR analysis of TSHR transcript expression (manuscript in preparation). It also confirms the preference for thyroid follicular cells obtained from GD patients in early assays developed to measure TSab (32). The increased receptor expression in GD is probably not due to treatment, since patients with a germline receptor mutation had undergone similar regimens and their cell surface TSHR expression is dramatically reduced. So is the increase the consequence or part of the cause of the autoimmune response to the TSHR? This would be difficult to resolve, for practical and ethical reasons, but may be possible by quantifying TSHR transcripts in fine needle aspirates of first-degree relatives of GD patients.

Perhaps the most interesting aspect of the study is the finding that surface expression of receptors with a gain-of-function mutation is greatly reduced in vivo, even when compared with normal thyroids. In vitro comparison of mutant and wild-type TSHR surface expression in non-thyroidal cells has shown that this is a feature of the majority of the activating mutants studied. Indeed it had been suggested that the true biological activity of a particular mutant form should take into account its low level of surface expression (23). Our demonstration of little or no basolateral membrane staining, with either A10 or T3-495, implies that the physiological intracellular trafficking of these activating mutations is impaired, as proposed for other mutated thyroid-specific proteins assessed in non-thyroidal cells (33).

In conclusion, the development and application of an immunocytochemical method for the TSHR has revealed wide variations in the level of receptor protein expression in normal and hyperthyroid glands. Different molecular mechanisms to generate the hyperthyroid state result in the lowest (mutation) and highest (autoimmunity) levels of receptor at the thyrocyte surface, the pathophysiological consequences of which merit further investigation.

\section{Acknowledgements}

The authors would like to thank Helmut Willgerodt, Pediatric Clinic, University of Leipzig, Germany and W von Petrykowski, Childrens Hospital, University of Freiburg, Germany for providing us with paraffin blocks. We also would like to thank Sabine Costagliola, Brussels, Belgium, Paul Banga, London, UK and Edwin Milgrom, Paris, France for providing us with antibodies used in this study.

\section{References}

1 Vassart G \& Dumont JE. The thyrotropin receptor and the regulation of thyrocyte function and growth. Endocrine Reviews 199213 596-611.

2 Libert F, Vassart G \& Parmentier M. Current developments in G-protein coupled receptors. Current Opinion in Cell Biology $19913218-252$.

3 Brabant G, Maenhaut C, Kohrle J, Scheumann G, Dralle H, Hoangvu C et al. Human thyrotropin receptor gene expression in thyroid and correlation to markers of thyroid differentiation and dedifferentiation. Molecular and Cellular Endocrinology 1991 82 R $7-R 12$.

4 Crisp MS, Lane C, Halliwell M, Wynford-Thomas D \& Ludgate M. Thyrotropin receptor transcripts in human adipose tissue. Journal of Clinical Endocrinology and Metabolism 199782 2003-2005.

5 Hoangvu C, Dralle H, Scheumann G, Maenhaut C, Horn R, Muhlen AV et al. Gene-expression of differentiation markers and 
dedifferentiation markers in normal and malignant human thyroid tissues. Experimental and Clinical Endocrinology 1992 $10051-56$.

6 Lazar V, Bidart JM, Caillou B, Mahe C, Lacroix L, Filetti S et al. Expression of the $\mathrm{Na}^{+} / \mathrm{I}^{-}$symporter gene in human thyroid tumors: a comparison study with other thyroid specific genes. Journal of Clinical Endocrinology and Metabolism $1999 \mathbf{8 4}$ 3228-3234.

7 Schuppert F, Deiters S, Rambusch E, Sierralta W, Dralle H \& Muhlen AV. TSH-receptor expression and human thyroid disease: relation to clinical, endocrine and molecular thyroid parameters. Thyroid $1996 \mathbf{6} 575-587$.

8 Schmid KW, Jasani B, Morgan JM \& Williams ED. Light microscopic immunohistochemical demonstration of thyroid stimulating hormone (TSH) receptors on normal rat thyroid cells. Journal of Histochemistry and Cytochemistry 198836 977-982.

9 Costagliola S, Alcalde L, Ruf J, Vassart G \& Ludgate M. Overexpression of the extracellular domain of the thyrotropin receptor in bacteria; production of thyrotropin-binding inhibiting immunoglobulins. Journal of Molecular Endocrinology 199413 $11-21$.

10 Loosfelt H, Pichon C, Jolivet A, Misrahi M, Caillou B, Jamous M et al. Two-subunit structure of the human thyrotropin receptor. PNAS 199289 3765-3769.

11 Nicholson LB, Vlase H, Graves P, Nilsson M, Molne J, Huang GC et al. Monoclonal antibodies to the human thyrotropin receptor: epitope mapping and binding to the native receptor on the basolateral plasma membrane of thyroid follicular cells. Journal of Molecular Endocrinology 199616 159-170.

12 Costagliola S, Rodien P, Many MC, Ludgate M \& Vassart G. Genetic immunization against the human thyrotropin receptor causes thyroiditis and allows production of monoclonal antibodies recognizing the native epitope. Journal of Immunology $1998 \mathbf{1 6 0}$ $1458-1465$.

13 Mizukami Y, Hashimoto T, Nonomura A, Michigishi T, Nakamura $\mathrm{S}$, Noguchi $\mathrm{M}$ et al. Immunohistochemical demonstration of thyrotropin (TSH)-receptor in normal and diseased human thyroid tissues using monoclonal antibody against recombinant human TSH-receptor protein. Journal of Clinical Endocrinology and Metabolism 1994 79 616-619.

14 Misrahi M, Ghinea N, Sar S, Saunier B, Jolivet A, Loosfelt H et al. Processing of the precursors of the human thyroid-stimulating hormone receptor in various eukaryotic cells (human thyrocytes, transfected L cells and baculovirus-infected insect cells). European Journal of Biochemistry 1994222 711-719.

15 Rapoport B, Chazenbalk GD, Jaume JC \& McLachlan SM. The thyrotropin (TSH) receptor: interaction with TSH and autoantibodies. Endocrine Reviews $199819673-716$.

16 Parma J, Duprez L, Van Sande J, Cochaux P, Gervy C, Mockel J et al. Somatic mutations in the thyrotropin receptor gene cause hyperfunctioning thyroid adenomas. Nature $1993 \mathbf{3 6 5} 649-651$.

17 Holzapfel HP, Fuhrer D, Wonerow P, Weinland G, Scherbaum WA \& Paschke R. Identification of constitutively activating somatic thyrotropin receptor mutations in a subset of toxic multinodular goitres. Journal of Clinical Endocrinology and Metabolism 199782 3885-3891.

18 Duprez L, Parma J, Van Sande J, Allgeier A, Leclere J, Schvartz C et al. Germline mutations in the thyrotropin receptor gene cause nonautoimmune autosomal dominant hyperthyroidism. Nature Genetics 19947 396-401.

19 Kopp P, Van Sande J, Parma J, Duprez L, Gerber H, Joss E et al. Congenital hyperthyroidism caused by a mutation in the thyrotropin-receptor gene. New England Journal of Medicine 1995 $332150-154$.

20 Fuhrer D, Mix M, Wonerow P, Richter I, Willgerodt H \& Paschke R. Variable phenotype associated with Ser505Asn-activating thyrotropin-receptor germline mutation. Thyroid $1999 \mathbf{9}$ $757-761$.

21 Paschke R \& Ludgate M. The thyrotropin receptor in thyroid diseases. New England Journal of Medicine 1997337 1675-1681.

22 Cetani F, Tonacchera M \& Vassart G. Differential effects of $\mathrm{NaCl}$ concentration on the constitutive activity of the thyrotropin and the luteinizing hormone chorionic gonadotrophin receptors. FEBS Letters $1996 \mathbf{3 7 8} 27-31$.

23 Parma J, Van Sande J, Swillens S, Tonacchera M, Dumont J \& Vassart G. Somatic mutations causing constitutive activity of the thyrotropin receptor are the major cause of hyperfunctioning thyroid adenomas: identification of additional mutations activating both the cyclic adenosine $3^{\prime}, 5^{\prime}$-monophosphate and inositol phosphate- $\mathrm{Ca}^{2+}$ cascades. Molecular Endocrinology 19959 $725-733$.

24 Fuhrer D, Wonerow P, Willgerodt H \& Paschke R. Identification of a new thyrotropin receptor germline mutation (Leu629Phe) in a family with neonatal onset of autosomal dominant nonautoimmune hyperthyroidism. Journal of Clinical Endocrinology and Metabolism 199782 4234-4238.

25 Morgan JM, Navabi H, Schmid KW \& Jasani B. Possible role of tissue bound calcium ions in citrate mediated high temperature antigen retrieval. Journal of Pathology 1994174 301-307.

26 Pileri SA, Roncador G, Ceccarelli C, Piccioli M, Briskomatis A, Sabbatini E et al. Antigen retrieval techniques in immunohistochemistry; comparison of different methods. Journal of Pathology $1997183116-123$.

27 Dutton CM, Joba W, Spitzweg C, Heufelder AE \& Bahn RS. Thyrotropin receptor expression in adrenal, kidney and thymus. Thyroid $19977879-884$.

28 Crisp M, Starkey K, Lane C, Ham J \& Ludgate M. Adipogenesis in thyroid eye disease. Investigative Ophthalmology and Vision Science $2000413249-3255$.

29 Fuhrer D, Warner J, Sequeira M, Paschke R, Gregory J \& Ludgate M. Novel TSHR germline mutation (Met463Val) masquerading as Graves' Disease in a large Welsh kindred with hyperthyroidism. Thyroid 200010 1035-1041.

30 Holzapfel HP, Wonerow P, von Petrykowski W, Henschen M, Scherbaum WA \& Paschke R. Sporadic congenital hyperthyroidism due to a spontaneous germline mutation in the thyrotropin receptor gene. Journal of Clinical Endocrinology and Metabolism 199782 3879-3884.

31 Costagliola S, Sunthorntepvarakul T, Migeotte I, VanSande J, Kajava AM, Refetoff S et al. Structure-function relationships of two loss-of-function mutations in the thyrotropin receptor. Thyroid 19999 995-1000.

32 Rapoport B, Takai NA \& Filetti S. Evidence for species specificity in the interaction between thyrotropin and thyroid-stimulating immunoglobulin and their receptor in thyroid disease. Journal of Clinical Endocrinology and Metabolism 198254 1059-1062.

33 Pohlenz J, Duprez L, Weiss RE, Vassart G, Refetoff S \& Costagliola S. Failure of membrane targeting causes the functional defect of two mutant sodium iodide symporters. Journal of Clinical Endocrinology and Metabolism 2000852366 -2369.

Received 6 August 2001

Accepted 23 October 2001 